\title{
The Effect of Occupational Stress on the Quality of Life of Pharmacists in Saudi Arabia
}

This article was published in the following Dove Press journal:

Risk Management and Healthcare Policy

\section{Yasser Almogbel (CD}

Department of Pharmacy Practice, College of Pharmacy, Qassim University, Buraidah, 5I452, Qassim, Saudi Arabia
Correspondence: Yasser Almogbel Department of Pharmacy Practice, College of Pharmacy, Qassim University, Buraidah, 5|452, Qassim, Saudi Arabia Tel +966 I6 301460I

Email y.almogbel@qu.edu.sa
Purpose: The job of a pharmacist is extremely demanding, and pharmacists play a vital role in improving the success of patients' treatment plans and disease management outcomes. The objective of this study was to evaluate the association between pharmacists' quality of life (QOL) and occupational stress in Saudi Arabia.

Methods: This was a prospective, paper-based, cross-sectional survey. The World Health Organization Quality of Life - Brief scale (WHOQOL-BREF) was used to evaluate quality of life, and the Effort-Reward Imbalance (ERI) scale was used to assess occupational stress. The two scales were administered to licensed pharmacists working in Saudi Arabia, and demographic data were collected. Descriptive and analytical statistical tests were performed. Multiple linear regression was conducted to evaluate the association between work stress and QOL.

Results: A total of 371 questionnaires were distributed, and 284 questionnaires were returned. The average age of the participants was $33.4 \pm 6.5$ years. Most were male $(61.2 \%)$, married $(62.9 \%)$, and had children (51.1\%). Multiple linear regression analysis showed significant negative relationships between stress $(\beta=-0.454 ; 95 \% \mathrm{CI},-0.697$ to $-0.211)$ and QOL, and between the presence of chronic diseases ( $\beta=3.779 ; 95 \% \mathrm{CI}, 0.597$ to 6.961) and QOL, when holding other variables constant. Also, a positive association between male sex ( $\beta=3.779 ; 95 \%$ CI, 0.597 to 6.961) and QOL was reported, when other variables were kept constant.

Conclusion: Occupational stress and the presence of chronic diseases were found to have a negative influence on pharmacists' QOL, while the male sex was associated with a better QOL. Moreover, QOL was linked to performance. Pharmacists are intensely involved in medication safety (use and administration), which might impact patients (at the micro-level) and the healthcare system (at the macro-level). Therefore, stress control is crucial to improve pharmacists' QOL and performance in relation to patient health.

Keywords: pharmacy profession, well-being, work climate, distress

\section{Introduction}

One out of every 370 hospitalized patients dies due to neglect or preventable errors. ${ }^{1}$ The safety culture of hospitals could be markedly improved by reducing medication errors, ${ }^{2}$ which contribute to morbidity, mortality, as well as medical and hospital expenses. ${ }^{3}$ Pharmacists play a major role in minimizing medication errors by conducting interventions that improve drug safety, including risk of adverse drug reaction evaluations, and the design of strategies for identifying individuals who are at risk of harmful drug reactions. ${ }^{3}$ A pharmacist's job requires expertise and the ability to interpret the ever-expanding information about medical technology and its environment. In fact, the expertise of pharmacists is directly related to patients' 
medical outcomes and safety. ${ }^{4}$ Pharmacists are required to safely administer medications to patients. ${ }^{4}$ Furthermore, they are required to perform their duties according to the hospital's criteria of accreditation and registration while meeting the standards implemented by insurance companies or the national health care scheme of a particular country. ${ }^{4}$ Thus, there is a need for highly skilled pharmacists who can play a vital role in the health team.

Pharmacy today is experiencing a transition from a career involving the simple delivery of a service (such as dispensing medication) in response to a prescriber's orders to one where the pharmacist must deliver a prescription for effective treatment in collaboration with the prescriber and other members of the healthcare team. ${ }^{5}$ Since the late $1960 \mathrm{~s}$, pharmacy associations and their proponents have advocated wider clinical functions for pharmacists, which go beyond the preparation, supply, and delivery of drugs, and a move toward direct patient care. ${ }^{6}$ This shift has markedly affected working pharmacists, the role of pharmacy education, and the continued education of practicing pharmacists. ${ }^{5}$ The creation of special practices and credentials has provided pharmacists with the opportunity to become more patient-centered in their focus. ${ }^{6}$ Each year, the number of credentialed specialties for pharmacists has increased; currently, there are 13 specialties. ${ }^{6}$ This places a greater burden of responsibility on pharmacists. ${ }^{4}$

In Saudi Arabia, pharmacists' duties have typically been restricted to the preparation and dispensing of prescriptions. ${ }^{7}$ Following recent changes, pharmacists' duties have expanded (mirroring those of Western countries), and pharmacists now find themselves part of the healthcare team that counsels patients and participates in therapeutic plans with physicians for the purpose of choosing the best options for patients. ${ }^{7,8}$

Pharmacists, due to their responsibilities, may be prone to stress. Those who function with less than an ideal amount of rest, work long hours, exceed their workload capacity, or have insufficient resources are at risk of exhaustion, discomfort, fatigue, and stress. ${ }^{4,9}$ The working environment affects a workers perception of their job. ${ }^{4,10}$ A supportive workplace, staff satisfaction, and encouragement provide a positive relationship, alleviating workplace pressures. ${ }^{11-13}$

Stress can be understood as the discrepancy between the person's requirements and the available resources that can be used to meet a requirement or need. ${ }^{14}$ Selye (1936) categorized stress into desirable stress, known as eustress, and undesirable stress, which is known as distress. ${ }^{15}$ Eustress is the general response to any request that is made. In contrast, distress or negative stress arises once the demand passes tolerability when the individual is no longer capable of sustaining homeostasis. ${ }^{16}$ Occupational or work-related stress is known to be caused by job stressors. ${ }^{17}$ Job stress can be described as the body's nonspecific negative reaction to job demands. ${ }^{18}$ It is commonly agreed that the experience of work-related stress differs widely across various professions and career positions. ${ }^{19}$

Many factors may render healthcare workers' roles stressful. ${ }^{20}$ Healthcare professionals may experience occupational stress because of imbalances in job demand, liability for patients, professional stigma, skills, salaries, workplace climate, available resources, and other organizational issues such as appreciation. ${ }^{17,20-23}$ A study conducted among 263 nurses and 107 pharmacists found that pharmacists had higher levels of stress than nurses. ${ }^{24}$

Practicing pharmacists are at risk of tremendous stress arising from various sources. ${ }^{25} \mathrm{~A}$ high proportion of pharmacists who have worked in institutional settings cite stress as the reason for leaving. A study conducted among 5410 pharmacists in the United States between 1983 and 1997 found that $11 \%$ of turnover was due to stress. ${ }^{26}$ Increased job demands and expectations create extra stress in pharmacy practice (eg, due to time constraints and the need for accuracy). ${ }^{27}$ Continuous exposure to time pressures, limited resources, and cognitive capacity make pharmacists susceptible to exhaustion and fatigue in the workplace. ${ }^{4}$ Pharmacists experiencing work stress are vulnerable to negative attitudes, and these negative emotions can persist for years. This causes serious emotional or physical harm and indirectly endangers patient safety through medication prescription errors. ${ }^{28}$ A 2004 study of 35 pharmacists in Ireland found that dispensing pharmacists were more stressed than consultant pharmacists. ${ }^{29}$ Moreover, occupational stress is significant from the onset of this career, as a study conducted among 200 pharmacy students and 420 medical students in Portugal found that pharmacy students reported higher levels of stress than medical students. ${ }^{30}$

The World Health Organization (WHO) defines quality of life (QOL) as

An individual's perception of their position in life in the context of the culture and value systems in which they live and in relation to their goals, expectations, standards, and concerns. $^{31}$ 
This term became common during the Second World War and emerged in social science research in the 1960s. Originally, QOL included the well-being of a community and was used to quantify the subjective perceptions of individuals. $^{32,33}$ Health-related quality of life (HRQoL) includes multiple dimensions which were derived by evaluating important factors that affect people's lives, including psychological, physical, and functional well-being. ${ }^{31}$ While the terms QOL and HRQoL can be used synonymously to identify the perceived medical condition, there are minor variations in these terms concerning size, depth, and context. ${ }^{34}$ QOL is a broad term addressing all facets of human life, while HRQoL focuses on the consequences of disease and especially the effect of treatment on QOL. ${ }^{35}$ A study conducted among 110 pharmacists in Iran found that the QOL among pharmacists was satisfactory. ${ }^{36}$

Several previous studies have explored QOL in both healthcare and non-healthcare professions. A 2014 study conducted in Brazil among 797 primary healthcare workers (doctors, nurses, technicians, nursing assistants, dentists, and other health care providers) found that overcommitment was associated with poor QOL. ${ }^{37}$ A 2013 study conducted in Malaysia among 698 automotive assembly employees found that stress negatively influenced quality of life. ${ }^{38}$ Another study conducted in 2010 on the coping strategies of 200 healthcare professionals found that those who applied coping strategies had less stress and a better QOL. ${ }^{39}$ Stress may be expressed through anger, fear, or anxiety, and has adverse impacts on work performance and QOL. ${ }^{40}$ A study conducted among healthcare employees in China investigated the association between the effect of workplace violence resulting from stress and its negative association with QOL. ${ }^{40}$ The resulting loss of QOL negatively affected job performance. A study conducted among 110 employees working in different departments of a tertiary general public hospital in India found that job stress correlated negatively with QOL scales. ${ }^{41}$ Another study conducted among doctors and nurses in India to evaluate the psychosocial predictors that affect QOL found a significant association between occupational stress and QOL. ${ }^{42}$ A 2013 study conducted in Greece among 246 nurses found that occupational stress is negatively linked to HRQoL. ${ }^{43}$ Another study conducted among 487 nurses working in the government system in Greece found that burnout, which is a long-term effect of stress, negatively affected the QOL of the participating nurses. ${ }^{44}$ Only one study has evaluated the relationship between stress and QOL among working pharmacists. This study was conducted in 2018 among 435 Lebanese pharmacists, and it found that higher stress has a significant influence on lower mental QOL. ${ }^{45}$ Another study conducted among 109 doctor of pharmacy students in the United States found a negative correlation between stress and mental QOL. ${ }^{46}$ Likewise, a study conducted among 110 pharmacy students in Ghana found a significant correlation between stress and QOL from the middle until the end of the semester. ${ }^{47}$

Because of the movement in pharmacy practice to include more specialties and domains, together with everyday job demands and the critical nature of a pharmacist's work in ensuring medication safety, an exploration of the relationship between stress and QOL among pharmacists is essential. Thus, the objective of this study was to evaluate the association between pharmacists' occupational stress and their QOL.

\section{Methods}

\section{Study Design and Data Sources}

A cross-sectional study was conducted using two scales along with demographics to determine the relationship between stress and QOL. These two scales were pretested, validated, self-administered, paper-based questionnaires. Ethical approval to conduct this research was obtained from the Regional Research Ethical Committee (institutional review board) before data collection. Data were gathered between July 2019 and April 2020 from Saudi pharmacists and at various sites across Saudi Arabia, including at academic institutions, hospitals, the pharmacy market, the drug industry, pharmacy gatherings, and conferences. A research assistant approached the attendees and asked them to participate. Prior to participation, a consent form was filled out. Participation was voluntary, and the participant could stop at any time and for any reason. The sample size was calculated using the G*Power software package (version 3.1.9). To calculate the required sample size, several assumptions were made: power, 0.99; alpha level, 0.05; number of predictors, 15; medium effect size, 0.15 . The required sample size using these assumptions is 257 participants.

\section{Participants}

The data collector requested pharmacists to fill out the survey together with the consent document. All Saudi pharmacists who agreed to participate signed the consent form and were given 25 minutes to complete the survey. All participants were notified that their participation was 
anonymous and voluntary. Also, participants were informed about the purposes of the study before commencing the data collection. All completed surveys were kept in sealed envelopes.

\section{Survey Design}

A back-translation process was performed by two independent translators who translated the questionnaire from English to Arabic. ${ }^{49}$ A survey translated into Arabic from a previously published study (21 items) was used; it matched the new short form of the Effort-Reward Imbalance (ERI) scale (16 items). ${ }^{50,51}$ Four specialist and consultant pharmacists evaluated the translated version of the survey. A translated, pretested, and validated survey version of The World Health Organization Quality of Life - Brief scale (WHOQOL-BREF) was used to evaluate the QOL. ${ }^{52}$ Both surveys were pilot-tested with 10 pharmacists, who were interviewed and asked to describe their understanding of the questionnaire; this was to verify its accuracy and understandability. Data were collected using the convenience sampling technique.

\section{Variables}

\section{Outcome Variables}

Recently, health assessments have been broadened to include assessments of the effects of disability, functional status, and impairment that are affecting everyday activities and behavior. ${ }^{53}$ Thus, the WHOQOL-BREF was used to evaluate the QOL of the pharmacists who participated in this study. Originally, the WHO developed the WHOQOL-100, and it was initially comprised of 100 questions. However, this scale was lengthy and timeconsuming. Therefore, a briefer version consisting of 26 questions was developed (ie, WHOQOL-BREF) to overcome these disadvantages. The WHOQOL-BREF scale is subcategorized into four domains. One question about sexual activity was removed because it was inappropriate for the conservative Saudi culture, and could have affected the study's approval or response rate.

\section{Independent Variables}

Predictors included socio-demographic information: age; sex; marital status; number of children; and monthly income. Participants were asked to indicate year of birth, income in Saudi Riyals (SAR; 3.75 Saudi Riyals = US\$1), and number of children as continuous variables. Variables relating to education and occupation were also collected, such as the highest college degree earned, total number of working hours per week, years of job experience, and job type. Years of experience and number of working hours per week were collected as continuous variables by allowing participants to write their answers down as numbers. There were six options to choose from for the highest degree earned: Bachelor's degree; Doctor of Pharmacy (Pharm. D.); Master's degree; general local or international residency; specialized local or international residency; and Doctor of Philosophy (PhD) in Pharmacy. This variable was recorded for the inferential statistics into non-postgraduate degrees, Bachelor's degree and Doctor of Pharmacy (Pharm. D.), and postgraduate degrees, including the other four higher degrees. Job type was divided into community pharmacists, hospital pharmacists, hospital clinical pharmacists, pharmaceutical companies (industry), pharmaceutical companies (marketing), university professors, and regulatory authorities. This covariate was recorded into a dichotomous variable for the inferential statistics. Having first obtained the permission of the author, occupational stress was measured using the ERI scale. ${ }^{51}$ Pharmacists were requested to answer the questions in such a way that they indicated how well the items reflected their full-time job environment. ${ }^{51}$ The ERI model is a structured self-reported test comprising three psychometric domains: 1) effort; 2) reward; and 3) over-commitment. $^{54}$ The ERI scale consists of 16 questions answered on a four-point Likert-type scale that covers the three prior mentioned domains. The four items were reverse-coded before the analyses, as directed in the scale manual. ${ }^{51}$

\section{Statistical Analyses}

Descriptive analyses were performed to explore categorical and continuous demographics, stress, and QOL. All independent variables with a $p$-value $\leq 0.2$ in the univariate test were added to the multiple linear regression analysis to control for any confounding variables that were statistically insignificant. ${ }^{55,56}$ All data obtained were encoded and entered using Microsoft Excel 2016, and the statistical analysis was conducted with Stata 16.

\section{Results}

Of the 371 questionnaires distributed, 284 were returned, which is a response rate of $76.5 \%$. Descriptive continuous and categorical statistics were applied to provide an overview of the sample (Tables 1 and 2). The mean age of the participants was $33.4 \pm 6.5$ years, and their average work experience was $8.08 \pm 7.2$ years. The average monthly 
income for the sample was SAR 16,366.75 \pm 6858.89 (US $\$ 4364.46 \pm \$ 1829.04)$. Most respondents were working in hospitals, and their total working hours per week were $41.24 \pm 10.21$. The average occupational stress using the ERI reported by respondents was $43.85 \pm 5.43$ across all domains. Based on the three items in the effort domain, the average score was $8.99 \pm 1.96$.

Regarding the reward domain, which includes seven items, participants scored $20.3 \pm 2.5$. The last six items comprised the over-commitment domain, which scored $14.45 \pm 3.0$. The average total QOL using WHOQOLBREF was $55.5 \pm 8.5$. The highest score was among the social relationships domain, at $15.4 \pm 3.3$. The remaining domains scored similarly, with a mean value of $13.7 \pm 2.6$, $13.6 \pm 2.1$, and $13.2 \pm 2.6$ for physical health, psychological, and environment, respectively. Overall, $61 \%$ of respondents were male, and $39 \%$ of respondents were female. The majority of respondents (62.9\%) reported that they were married, while $35 \%$ reported being single (two participants disclosed that they were divorced, no participants reported being widowed). Although a large portion of respondents reported being married, $49 \%$ reported having no children. Of the remaining respondents, $14 \%$ reported having one child, $11 \%$ reported having two children, $11 \%$ reported having three children, and around $8 \%$ of participants reported having four children. Interestingly, the participants who reported having six children $(4.4 \%)$ were more numerous than those with five children (2\%). Of the respondents, $17.6 \%$ reported having been diagnosed with a chronic disease. Regarding

Table I Continuous Baseline Characteristics of the Participants $(n=284)^{a}$

\begin{tabular}{|l|l|}
\hline Characteristics & Mean ( $\mathbf{\text { SD}}$ ) \\
\hline Age (years) & $33.4(6.5)$ \\
Income in SAR (\$0.266) & $16.366 .8(6858.9)$ \\
Experience in years; mean \pm SD & $8.1(7.2)$ \\
Total working hours per week; mean \pm SD & $41.24(10.2)$ \\
The total occupational stress using the ERI & $43.9(5.4)$ \\
The ERI Effort Domain & $8.9(1.9)$ \\
The ERI Reward scale Domain & $20.3(2.5)$ \\
The ERI Over-commitment Domain & $14.5(3.0)$ \\
Total QOL using WHOQOL-BREF & $55.5(8.5)$ \\
Physical health & $13.7(2.6)$ \\
Psychological & $13.6(2.1)$ \\
Social relationships & $15.3(3.3)$ \\
Environment & $13.1(2.6)$ \\
\hline
\end{tabular}

Note: ${ }^{2}$ Numbers may not add up to 284 due to missing values.
Table 2 Categorical Baseline Characteristics of the Participants $(\mathrm{n}=284)^{\mathrm{a}}$

\begin{tabular}{|c|c|}
\hline Characteristics & $\begin{array}{l}\text { Number of Participants } \\
\text { (Percentage) }\end{array}$ \\
\hline \multicolumn{2}{|l|}{ Sex } \\
\hline Male & $170(6 \mid .3)$ \\
\hline Female & $108(38.9)$ \\
\hline \multicolumn{2}{|l|}{ Marital status } \\
\hline Single & $98(35.0)$ \\
\hline Married & $176(62.9)$ \\
\hline Divorced & $6(2.1)$ \\
\hline Widowed or widower & $0(0.0)$ \\
\hline \multicolumn{2}{|l|}{ Chronic disease } \\
\hline Presence of chronic disease & $50(17.6)$ \\
\hline Absence of chronic disease & $234(82.4)$ \\
\hline \multicolumn{2}{|l|}{ Number of children } \\
\hline Zero & $133(48.9)$ \\
\hline One & $39(14.3)$ \\
\hline Two & $31(11.4)$ \\
\hline Three & $30(11.0)$ \\
\hline Four & $22(8.1)$ \\
\hline Five & $5(1.8)$ \\
\hline Six children and more & $12(4.4)$ \\
\hline \multicolumn{2}{|l|}{ Education level } \\
\hline Bachelor's degree & $146(52.7)$ \\
\hline Pharm.D. degree & $77(27.8)$ \\
\hline Master's degree & $31(11.2)$ \\
\hline $\begin{array}{l}\text { General local or international } \\
\text { residency }\end{array}$ & $2(0.7)$ \\
\hline $\begin{array}{l}\text { Specialized local or } \\
\text { international residency) }\end{array}$ & $5(1.8)$ \\
\hline Ph.D. degree & $16(5.8)$ \\
\hline \multicolumn{2}{|l|}{ Job title } \\
\hline Community pharmacist & $3(1.1)$ \\
\hline Hospital pharmacist & $|8|(65.8)$ \\
\hline Hospital clinical pharmacist & $23(8.4)$ \\
\hline $\begin{array}{l}\text { Pharmaceutical companies } \\
\text { (industry) }\end{array}$ & $10(3.5)$ \\
\hline $\begin{array}{l}\text { Pharmaceutical companies } \\
\text { (marketing) }\end{array}$ & $18(6.6)$ \\
\hline University professor & $20(7.3)$ \\
\hline Regulatory authorities & I $(0.4)$ \\
\hline Others & $19(6.9)$ \\
\hline
\end{tabular}

Note: a Numbers may not add up to 284 due to missing values.

highest education, respondents were mostly bachelor's degree holders $(52.7 \%)$, followed by Pharm. D. degree holders $(28 \%)$. Of the remaining participants, $11.2 \%$ 
Table 3 Univariate Linear Regression Analysis of Factors Associated with QOL Among Pharmacists in Saudi Arabia

\begin{tabular}{|c|c|c|c|c|}
\hline \multirow[t]{2}{*}{ Variable } & \multirow[t]{2}{*}{ Beta Coefficient } & \multicolumn{2}{|c|}{ 95\% Confidence Interval } & \multirow[b]{2}{*}{$p$-value } \\
\hline & & Lower & Upper & \\
\hline Stress & -0.492 & -0.686 & -0.298 & $<0.001 *$ \\
\hline Age & 0.125 & -0.081 & 0.332 & 0.232 \\
\hline \multicolumn{5}{|l|}{ Sex } \\
\hline Female & Ref. & & & \\
\hline Male & 2.855 & 0.295 & 5.415 & $0.029 *$ \\
\hline \multicolumn{5}{|l|}{ Marital status } \\
\hline Non-married & Ref. & & & \\
\hline Married & 0.829 & -1.783 & 3.440 & 0.532 \\
\hline Income in SAR $(\$ 0.266) / 1000$ & 0.0594 & -0.144 & 0.263 & 0.566 \\
\hline Having children & 1.763 & -0.738 & 4.265 & 0.166 \\
\hline \multicolumn{5}{|l|}{ Chronic disease } \\
\hline Presence of chronic disease & -3.799 & -7.125 & -0.474 & $0.025^{*}$ \\
\hline Absence of chronic disease & Ref. & & & \\
\hline \multicolumn{5}{|l|}{ Education level } \\
\hline Non-post graduate degrees & Ref. & & & \\
\hline Post graduate degrees & 1.331 & -1.685 & 4.347 & 0.385 \\
\hline Experience in years & 0.123 & -0.059 & 0.306 & 0.183 \\
\hline Total working hours/week & -0.032 & -0.177 & 0.113 & 0.664 \\
\hline \multicolumn{5}{|l|}{ Job type } \\
\hline Non-Hospital pharmacist & Ref. & & & \\
\hline Hospital pharmacist & -2.143 & -5.925 & 1.638 & 0.265 \\
\hline
\end{tabular}

Note: ${ }^{*} \mathrm{p}<0.05$.

indicated having a master's degree and $5.78 \%$ reported having a Ph.D. Few participants reported having general local or international residency $(0.72 \%)$ or specialized local or international residency (1.81\%).

Regarding the participants' job type, most of the participants worked in hospitals. Approximately $66 \%$ of respondents were hospital pharmacists, and $8.4 \%$ were clinical pharmacists. In addition, $7.3 \%$ of respondents were University professors, and $10 \%$ of respondents reported working as pharmacists in pharmaceutical companies. Those working in pharmaceutical companies were divided between industry (3.5\%) and marketing $(6.6 \%)$. Only one participant reported that he was from regulatory affairs. Around $7 \%$ of respondents reported other, which included administrative and quality in different sectors. Univariate analyses were conducted to explore the association between covariates such as demographics, factors associated with work, and occupational stress (Table 3). A simple linear regression analysis indicated a positive relationship between QOL and occupational stress ( $\beta=-0.492 ; 95 \% \mathrm{CI},-0.686$ to -0.298 ). Another positive association was found between male sex and better QOL ( $\beta=2.855$; 95\% CI, 0.295 - 5.415). Unsurprisingly, pharmacists with a chronic disease reported a low QOL $(\beta=-3.799$; $95 \% \mathrm{CI},-7.125$ to -0.474 ).

A multiple linear regression was performed to account for confounders (Table 4). A significant negative association was found between occupational stress and QOL ( $\beta$ $=-0.454 ; 95 \% \mathrm{CI},-0.6096$ to -0.212 ) when other variables were kept constant. In addition, male sex is positively associated with QOL ( $\beta=3.313$; 95\% CI, $0.446-$ 6.181) when other variables are kept constant. Finally, chronic diseases are associated with adverse QOL $(\beta$ $=-3.781 ; 95 \% \mathrm{CI},-7.237$ to -0.326 ), when other variables kept constant. 
Table 4 Multivariate Linear Regression Analysis of Factors Associated with Quality of Life Among Pharmacists in Saudi Arabia

\begin{tabular}{|c|c|c|c|c|}
\hline \multirow[t]{2}{*}{ Variables } & \multirow[t]{2}{*}{ Beta Coefficient } & \multicolumn{2}{|c|}{ 95\% Confidence Interval } & \multirow[b]{2}{*}{$p$-value } \\
\hline & & Lower & Upper & \\
\hline Stress & -0.454 & -0.697 & -0.212 & $<0.00 I^{*}$ \\
\hline \multicolumn{5}{|l|}{ Sex } \\
\hline Female & Ref. & & & \\
\hline Male & 3.313 & 0.446 & 6.181 & $0.024^{*}$ \\
\hline Having children & 0.509 & -2.553 & 3.572 & 0.743 \\
\hline \multicolumn{5}{|l|}{ Chronic disease } \\
\hline Presence of chronic disease & -3.781 & -7.237 & -0.326 & 0.032 \\
\hline Absence of chronic disease & Ref. & & & \\
\hline Experience in years & 0.054 & -0.168 & 0.2759 & 0.630 \\
\hline
\end{tabular}

Note: ${ }^{*}<0.05$.

\section{Discussion}

The job of a pharmacist is extremely demanding, and any mistake can severely impact patients' lives. This study was aimed at investigating the effect of work stress on pharmacists' QOL. We found that Saudi male pharmacists had better QOL. We also found that chronic disease and occupational stress negatively affected the QOL of pharmacists in Saudi Arabia.

The average age of this study's participants was 31 years, which indicates that most of the respondents are in the first and second tertiles of their working lives. This conclusion was also supported by their years of experience, the duration of which was $8.1 \pm 7.2$ years on average, assuming a work-life age of approximately 40 years. This may be because, in the past 15 years, the number of pharmacy colleges in Saudi Arabia has greatly increased, from one college in 1957 to now more than 20 colleges offering a bachelor's degree, Pharm. D., and post-graduate degrees. With the increase of national graduated pharmacists, non-national pharmacists were replaced. This has led to a large increase in the number of young pharmacists.

The Saudi average monthly wage for all sectors is SAR 10,238 (\$2730), which is lower than the average income reported by our sample of pharmacists, which was SAR $16,366 \pm 6858(\$ 4364 \pm 1829),{ }^{57}$ and is consistent with pharmacists' income in the United States. Although Saudi pharmacists do not earn as much as those in the United States, their salaries are higher than the median wage in the United States. Pharmacists working in the United States earn $\$ 10,459$ per month, and the median income for all workers in the United States is $\$ 3890$ per month. ${ }^{58,59}$ Regarding working hours, the pharmacists in this study worked for $41.2 \pm 10.2$ hours per week, which is within the limits set for all workers in Saudi Arabia. Labor law in the country stipulates that workers are not allowed to work for more than 8 hours per day or 48 hours per week. ${ }^{60}$ The mean hours per week was within the upper portion of the Saudi labor law, and the standard deviation was quite large $( \pm 10.2)$. This may be due to differences between jobs. However, this factor did not become significantly associated with QOL.

Most of the respondents reported their place of employment to be a hospital. In Saudi Arabia, most Saudis prefer government jobs because of the job security afforded. Thus, more participants worked in hospitals than in other sectors. Furthermore, for pharmacists, more hospital jobs are available in cities than in other sectors. A shift away from the provision of government jobs toward private contracted jobs has been noted; however, this is difficult to confirm.

Apart from sex, none of the demographic factors were significantly associated with QOL. In earlier studies, sex differences were not evaluated, and the results obtained from men were wrongly generalized to include women. ${ }^{61}$ Thus, exploring sex as a variable is crucial because of the different roles played by the sexes among Saudi pharmacists. A study conducted among 210 civil servants in Nigeria found that men were better able to adapt to work stressors than women. ${ }^{62}$ Another study conducted among 545 patients diagnosed with panic disorder in Korea found that the HRQoL among women was significantly lower than it was among men. ${ }^{63}$ However, other studies did not find a sex-related difference in terms of stress or QOL. 
Furthermore, a 2016 study conducted with 249 Italian participants found no difference in work-related stress between the sexes. ${ }^{64}$ Another study conducted among 11,636 Dutch employees found no difference in the wellbeing of men and women. ${ }^{65}$ The current study showed a significant positive association between males and QOL. This is probably because the cultural roles women play as mothers, wives, and caregivers in Saudi Arabia take precedence over their roles in demanding pharmacist jobs. Family obligations for women were found to be strongly and negatively correlated with the number of hours worked each week. ${ }^{66}$

Not surprisingly, having a chronic condition was found to be significantly associated with low QOL in the univariate analysis. There are QOL scales available for specific diseases, such as the Asthma Quality of Life Questionnaire. It confirmed that chronic diseases, such as asthma, may impact the two main domains in QOL scales (ie, physical activity and psychological life). ${ }^{67}$ The results of the current study are consistent with those of a study conducted in 2018 among 4803 Cambodian adults diagnosed with chronic disease. This study found that patients diagnosed with chronic diseases had poor QOL. ${ }^{68}$ Another study conducted among 760 adult Chinese patients found that depression and osteoarthritis of the knees were associated with low HRQoL. ${ }^{69}$ Furthermore, a study conducted among 2560 Turkish patients to evaluate the effect of mental disorders and diabetes-related hypertension on QOL found that these diseases negatively affected QOL. ${ }^{70}$

The ERI scale was used to evaluate occupational stress. The average score (43.5) was higher than the 50th percentile (score $=32$ ) of the score, which indicates that the participants face some stress (this scale does not establish a score for stress). This scale is sub-divided into three domains. The first domain is about effort, and includes three items. The mean score was around eight, which is more than half of the total score of the three items (12). This indicates that participants did not report positive feedback about the effort, which concerns the demands of the work environment.

The participant's average score in the reward domains (seven items) was 20. Also, this score was more than the 50th percentile (14), which implies that the participants did not give the job rewarding positive feedback. The last six items were for the over-commitment domain. The mean average was 14.5 , which was more than half of the total score of this domain. Occupational stress levels vary significantly across diverse occupations and job positions, and there was no other occupational group with which a comparison could be made. Nonetheless, we found that the total score of the ERI and its domains separately was more than half of the total score and of each domain. ${ }^{19}$ This result was consistent with a previous study conducted among 263 nurses and 107 pharmacists, which showed that stress rates were increased for pharmacists. ${ }^{24}$ Furthermore, between 1983 and 1997, a study conducted across 5410 pharmacists in the United States reported that $11 \%$ of job turnover was attributed to stress. ${ }^{26}$ Our findings were also consistent with the experiences of pharmacist students in a study carried out in Portugal. Across 420 pharmacy and medical students, pharmacy students documented greater stress levels than medical students. ${ }^{30}$

It has previously reported that dispensing pharmacists are more stressed than consultant pharmacists in a study conducted in Ireland. ${ }^{29}$ However, when we ran inferential statistics between job description and occupational stress, we did not find an association with occupational stress. Occupational stress may occur as a nonspecific negative response of the body. ${ }^{18}$

The reported WHOQOL-BREF for each domain was less than the full score, which was 20. The average score for each domain of physical health, psychological, social relationships, and environment was less than the full score (the full health), and they tended to reach half, except for social relationships. Our results are similar to those of a study conducted among Iranian pharmacists, which used a general health perception scale and found that there was $65 \%$ satisfaction concerning quality of life. ${ }^{36}$

The main purpose of the current study was to explore the association between stress and QOL. The final multiple linear regression analysis showed a negative association between these two variables. This finding is consistent with those of previous studies conducted among healthcare and non-healthcare providers. Anger, fear, and anxiety, all of which present as stress, may negatively affect work performance and QOL. ${ }^{40}$

In non-healthcare workers (698 car manufacturing staff in Malaysia), it was revealed that stress had a detrimental effect on QOL. ${ }^{38}$ In a 2010 study evaluating stress-coping strategies among a sample of 200 healthcare workers, stress reduction was linked to higher QOL. ${ }^{39}$ A study conducted among Chinese healthcare employees found that stressors led to workplace violence, which was linked to low QOL. ${ }^{40}$ A study performed among 110 staff (of various occupations) in a public hospital in India reported that work stress was adversely associated with QOL. ${ }^{41}$ 
Likewise, a survey conducted among physicians and nurses in India to quantify the psychosocial factors affecting QOL revealed a strong relationship between job stressors and QOL. ${ }^{42}$ A study among 246 Greek nurses showed that workplace stress is adversely correlated with HRQoL. ${ }^{43}$ In a study conducted among 487 nurses, the operating governmental program indicated that burnout due to long-term stress had a detrimental effect on QOL. ${ }^{44}$ In 2014, a study conducted among 797 Brazilian primary healthcare workers found that over-commitment was associated with poor QOL. ${ }^{37}$

Although the relationship between occupational stress and QOL has been studied extensively, only one previous study was reported involving pharmacists. A study conducted between 435 pharmacists from Lebanon found a significant association between higher stress and lower mental QOL. ${ }^{45}$ At the pharmacy student level, two studies found a significant association between stress and QOL. The first, conducted in the United States among 109 Pharm.D. students, found a negative correlation between mental QOL and stress. ${ }^{46}$ Another study conducted in Ghana among 110 students found a correlation between QOL and stress from the middle until the end of the semester. ${ }^{47}$ Since occupational stress affected QOL negatively, it can be categorized as distress. ${ }^{16}$

There are several limitations to the present study. Since external validity is limited to a population like the study population, cross-sectional analyses could pose concerns about cause and effect, but not about the relationships between variables. Since a convenient sampling technique was used, the potential impact of non-respondents could not be evaluated. The current study included a five-page paper-based survey. Therefore, missing values may have affected the survey results, particularly answers to questions included toward the end of the survey. Furthermore, although we assured the participants of their privacy, they may not have been fully transparent in their responses owing to social reasons. Also, this study could not focus on a particular sector, such as hospitals, because of the rejection rate.

Safety procedures are vital in preventing medication errors. $^{2,3}$ Qualified pharmacists play a major role in ensuring medication safety according to the high standards of the pharmaceutical services required., ${ }^{3,4}$ Over time, the role of pharmacists has evolved from dispensing medication according to a prescriber's instructions to offering accurate recommendations for prescriptions and treatment, in collaboration with the prescriber. ${ }^{5}$
With Saudi Arabia's recent advances in pharmacy career opportunities, which mirror similar practices in Western countries, pharmacists are now involved in providing direct care to the patient as part of the healthcare team. ${ }^{7,8}$ The recent expansion of pharmacy career opportunities has increased the demand placed on pharmacists to provide high service standards. Prolonged exposure to pressures, scarce resources, and diminished cognitive abilities have led pharmacists to experience fatigue and exhaustion. ${ }^{4}$ Increasing demands coupled with low resources creates job stress. ${ }^{14}$ Owing to this stress, pharmacists experience low QOL. High QOL is often considered a result of successful career development. ${ }^{71}$ Poor QOL negatively affects job performance and might indirectly affect patients. ${ }^{39}$ Thus, a low standard of performance by pharmacists can endanger patients' lives. Work stress and low QOL may cause a lack of job efficiency and early burnout. ${ }^{72}$ Hence, solutions for alleviating work stress are strongly encouraged to improve patient outcomes. Future studies should focus on identifying and modifying the occupational stressors for pharmacists, starting with known stressors of healthcare professionals, including task demand imbalances, patient liability, skills, wages, working environment, available resources, and appreciation in each sector. ${ }^{17,20-23}$

\section{Conclusion}

To the knowledge of the researcher, this is the first study to investigate the relationship between occupational stress and QOL among Saudi pharmacists. Occupational stress adversely affects QOL among pharmacists. Since medication and administration safety is largely dependent on pharmacists, it is important to explore the effect of work stress on their QOL. Overall, the findings of our study shed light on the association between pharmacists' stress and QOL, which potentially impacts patients' lives. Research suggests that stress control can result in improved physical and mental health for employees. ${ }^{72}$ Interventional studies are required to alleviate pharmacists' stress.

\section{Abbreviations}

ERI, Effort-Reward Imbalance; QOL, quality of life; WHOQOL-BREF, World Health Organization Quality of Life - Brief; HRQoL, health-related quality of life; SAR, Saudi Riyals. 


\section{Ethics Approval and Consent to Participate}

This study was approved by the Qassim Region Research Ethics Committee (research number: 1440-2297987). Furthermore, this study was performed in accordance with the Declaration of Helsinki.

\section{Acknowledgments}

The researcher would like to thank the Deanship of Scientific Research, Qassim University, for funding the publication of this project.

\section{Disclosure}

The authors declare that they have no competing interests.

\section{References}

1. KevinMD.com. Why one-third of hospitals will close by 2020; 2012. Available from: https://www.kevinmd.com/blog/2012/03/onethirdhospitals-close-2020.html. Accessed July 8, 2020.

2. Samsuri S, Lin L, Fahrni M. Safety culture perceptions of pharmacists in Malaysian hospitals and health clinics: a multicentre assessment using the safety attitudes questionnaire. BMJ Open. 2015;5(11): e008889. doi:10.1136/bmjopen-2015-008889

3. Guchelaar H-J, Colen HBB, Kalmeijer MD, et al. Medication errors: hospital pharmacist perspective. Drugs. 2005;65(13):1735-1746. doi:10.2165/00003495-200565130-00001

4. Lan Y-L, Huang W-T, Kao C-L, et al. The relationship between organizational climate, job stress, workplace burnout, and retention of pharmacists. J Occup Health. 2020;62(1):e12079. doi:10.1002/ 1348-9585.12079

5. Johnson TJ. Pharmacist workforce in 2020: implications of requiring residency training for practice. Am J Health Syst Pharm. 2008;65 (2):166-170. doi:10.2146/ajhp070231

6. Goldenshteyn F, Dopheide J, Lou M. Do pharmacist employers prefer or require board certification? J Am Pharm Assoc (2003). 2020;60 (1):66-71. doi:10.1016/j.japh.2019.09.015

7. Haseeb A, Elrggal M. Recommendations for the role of the pharmacist in Saudi Arabia. Arch Pharm Pract. 2013;4(10):4103. doi:10.4103/2045-080X.119069

8. Al-Jedai A, Qaisi S, Al-Meman A. Pharmacy practice and the health care system in Saudi Arabia. Can J Hosp Pharm. 2016;69 (3):231-237. doi:10.4212/cjhp.v69i3.1561

9. Rose CL, Murphy LB, Byard L, et al. The role of the big five personality factors in vigilance performance and workload. Eur J Pers. 2002;16(3):185-200. doi:10.1002/per.451

10. Manning ML, Davidson M, Manning RL. Measuring tourism and hospitality employee workplace perceptions. Int $J$ Hosp Manag. 2005;24(1):75-90. doi:10.1016/j.ijhm.2004.05.001

11. Allen TD. Family-supportive work environments: the role of organizational perceptions. $J$ Vocat Behav. 2001;58(3):414-435. doi:10.1006/jvbe.2000.1774

12. Casper WJ, Buffardi LC. Work-life benefits and job pursuit intentions: the role of anticipated organizational support. $J$ Vocat Behav. 2004;65(3):391-410. doi:10.1016/j.jvb.2003.09.003

13. Behson SJ. The relative contribution of formal and informal organizational work-family support. $J$ Vocat Behav. 2005;66(3):487-500. doi:10.1016/j.jvb.2004.02.004
14. Le Fevre ML, Matheny J, Kolt GS. Eustress, distress, and interpretation in occupational stress. J Manag Psychol. 2003;18(7):726-744. doi: $10.1108 / 02683940310502412$

15. Tan SY, Yip A. Hans Selye (1907-1982): founder of the stress theory. Singapore Med J. 2018;59(4):170-171. doi:10.11622/smedj.2018043

16. Sarafino EP, Smith TW. Health Psychology: Biopsychosocial Interactions. Danvers, MA: John Wiley \& Sons; 2014.

17. Qiao S, Li X, Zhou Y, et al. Attitudes toward evidence-based practices, occupational stress and work-related social support among health care providers in China: a SEM analysis. PLoS One. 2018;13 (8):e0202166. doi:10.1371/journal.pone.0202166

18. Eckel F, Caiola S. Managing stress of the employee. In: Noel MW, Bootman JL, editors. Human Resource Management in Pharmacy Practice. Rockville, MD: Aspen Systems Corporation; 1983:229-249.

19. Johnson S, Cooper C, Cartwright S, et al. The experience of workrelated stress across occupations. J Manag Psychol. 2005;20 (2):178-187. doi:10.1108/02683940510579803

20. Gollwitzer PM, Mayer D, Frick $\mathrm{C}$, et al. Promoting the self-regulation of stress in health care providers: an internet-based intervention. Front Psychol. 2018;9:838. doi:10.3389/ fpsyg. 2018.00838

21. Rössler W. Stress, burnout, and job dissatisfaction in mental health workers. Eur Arch Psychiatry Clin Neurosci. 2012;262(2):S65-S69. doi:10.1007/s00406-012-0353-4

22. Pedrazza M, Berlanda S, Trifiletti E, et al. Exploring physicians' dissatisfaction and work-related stress: development of the PhyDis scale. Front Psychol. 2016;7:1238. doi:10.3389/fpsyg.2016.01238

23. Ha PN, Chuc NTK, Hien HT, et al. HIV-related stigma: impact on healthcare workers in Vietnam. Glob Public Health. 2013;8(sup1): S61-S74. doi:10.1080/17441692.2013.799217

24. Wolfgang AP, Perri III M, Wolfgang CF. Job-related stress experienced by hospital pharmacists and nurses. Am J Hosp Pharm. 1988;45(6):1342-1345.

25. Boyle TA, Bishop A, Morrison B, et al. Pharmacist work stress and learning from quality related events. Res Soc Adm Pharm. 2016;12 (5):772-783. doi:10.1016/j.sapharm.2015.10.003

26. Mott DA. Pharmacist job turnover, length of service, and reasons for leaving, 1983-1997. Am J Health Syst Pharm. 2000;57(10):975-984. doi:10.1093/ajhp/57.10.975

27. Johnson SJ, O'Connor EM, Jacobs S, et al. The relationships among work stress, strain and self-reported errors in UK community pharmacy. Res Soc Adm Pharm. 2014;10(6):885-895. doi:10.1016/j. sapharm.2013.12.003

28. Leung M-Y, Liang Q, Olomolaiye P. Impact of job stressors and stress on the safety behavior and accidents of construction workers. J Manag Eng. 2016;32(1):04015019. doi:10.1061/(ASCE)ME.19435479.0000373

29. Lapane KL, Hughes CM. Baseline job satisfaction and stress among pharmacists and pharmacy technicians participating in the Fleetwood Phase III study. Consult Pharm. 2004;19(11):1029-1037. doi:10.4140/TCP.n.2004.1029

30. Silva R, Figueiredo-Braga M. Is it more stressful to become a physician or a pharmacist? A study on medical and pharmacy students' psychological state: PS228. Porto Biomed J. 2017;2 (5):238. doi:10.1016/j.pbj.2017.07.145

31. WHOQOL GROUP T. Development of the World Health Organization WHOQOL-BREF quality of life assessment. Psychol Med. 1998;28(3):551-558. doi:10.1017/S0033291798006667

32. Campbell A. Subjective measures of well-being. Am Psychol. 1976;31(2):117-124. doi:10.1037/0003-066X.31.2.117

33. Farquhar M. Definitions of quality of life: a taxonomy. $J$ Adv Nurs. 1995;22(3):502-508. doi:10.1046/j.1365-2648.1995.22030502.x

34. Wenger NK, Mattson ME, Furberg CD, et al. Assessment of quality of life in clinical trials of cardiovascular therapies. Am J Cardiol. 1984;54(7):908-913. doi:10.1016/S0002-9149(84)80232-5 
35. Guyatt GH, Ferrans CE, Halyard MY, et al. Exploration of the value of health-related quality-of-life information from clinical research and into clinical practice. Mayo Clin Proc. 2007;82(10):1229-1239. doi: $10.4065 / 82.10 .1229$

36. Majd M, Hashemian F, Younesi Sisi FY, et al. Quality of life and job satisfaction of dispensing pharmacists practicing in Tehran private-sector pharmacies. Iran J Pharm Res. 2012;11(4):1039-1044.

37. Teles MAB, Barbosa MR, Vargas AMD, et al. Psychosocial work conditions and quality of life among primary health care employees: a cross sectional study. Health Qual Life Outcomes. 2014;12(1):72. doi:10.1186/1477-7525-12-72

38. Rusli BN, Edimansyah BA, Naing L. Working conditions, self-perceived stress, anxiety, depression and quality of life: a structural equation modelling approach. BMC Public Health. 2008;8(1):48. doi:10.1186/1471-2458-8-48

39. Koinis A, Giannou V, Drantaki V, et al. The impact of healthcare workers job environment on their mental-emotional health. Coping strategies: the case of a local general hospital. Health Psychol Res. 2015;3(1):1984. doi:10.4081/hpr.2015.1984

40. Lin W-Q, Wu J, Yuan L-X, et al. Workplace violence and job performance among community healthcare workers in China: the mediator role of quality of life. Int $J$ Environ Res Public Health. 2015;12(11):14872-14886. doi:10.3390/ijerph121114872

41. Sule R, Thadasare H, Sonavane S, et al. A study of job satisfaction, job stress and quality of life in auxiliary health care workers of a public tertiary general hospital. J Psychosoc Rehabil Ment Health. 2017;4(1):23-27. doi:10.1007/s40737-017-0078-9

42. Kumar A, Bhat PS, Ryali S. Study of quality of life among health workers and psychosocial factors influencing it. Ind Psychiatry $J$. 2018;27(1):96-102. doi:10.4103/ipj.ipj_41_18

43. Sarafis P, Rousaki E, Tsounis A, et al. The impact of occupational stress on nurses' caring behaviors and their health-related quality of life. BMC Nurs. 2016;15(1):56. doi:10.1186/s12912-016-0178-y

44. Anagnostopoulos F, Niakas D. Job burnout, health-related quality of life, and sickness absence in Greek health professionals. Eur Psychol. 2010;15(2):132-141. doi:10.1027/1016-9040/a000013

45. Sacre H, Obeid S, Choueiry G, et al. Factors associated with quality of life among community pharmacists in Lebanon: results of a cross-sectional study. Pharm Pract. 2019;17(4):1613. doi:10.18549/ PharmPract.2019.4.1613

46. Marshall L, Allison A, Nykamp D, et al. Perceived stress and quality of life among doctor of pharmacy students. Am J Pharm Educ. 2008;72(6):137. doi:10.5688/aj7206137

47. Opoku-Acheampong A, Kretchy IA, Acheampong F, et al. Perceived stress and quality of life of pharmacy students in the University of Ghana. BMC Res Notes. 2017;10(1):115. doi:10.1186/s13104-017-2439-6

48. Faul F, Erdfelder E, Lang A-G, et al. G* Power 3: a flexible statistical power analysis program for the social, behavioral, and biomedical sciences. Behav Res Methods. 2007;39(2):175-191. doi:10.3758/ BF03193146

49. Brislin RW. Back-translation for cross-cultural research. J Cross Cult Psychol. 1970;1(3):185-216. doi:10.1177/135910457000100301

50. Almadi T, Cathers I, Chow CM. An Arabic version of the effort-reward imbalance questionnaire: translation and validation study. Psychol Rep. 2013;113(1):1287-1302. doi:10.2466/08.14. PR0.113x10z7

51. Siegrist J, Li J, Montano D. Psychometric Properties of the EffortReward Imbalance Questionnaire. Germany: Düsseldorf University; 2014.

52. Ohaeri J, Awadalla A. The reliability and validity of the short version of the WHO quality of life instrument in an Arab general population. Ann Saudi Med. 2009;29(2):98-104. doi:10.4103/0256-4947.51790

53. World Health Organization. WHOQOL-Bref: Introduction, Administration, Scoring and Generic Version of the Assessment: Field Trial Version, December 1996. Geneva, Switzerland: World Health Organization; 1996.
54. Siegrist J, Starke D, Chandola T, et al. The measurement of effort-reward imbalance at work: European comparisons. Soc Sci Med. 2004;58(8):1483-1499. doi:10.1016/S0277-9536(03)00351-4

55. Maldonado G, Greenland S. Simulation study of confounder-selection strategies. Am $\quad J$ Epidemiol. 1993;138 (11):923-936. doi:10.1093/oxfordjournals.aje.a116813

56. Vittinghoff E, Glidden DV, Shiboski SC, et al. Regression Methods in Biostatistics: Linear, Logistic, Survival, and Repeated Measures Models. Boston, MA: Springer Science \& Business Media; 2011.

57. GASTAT: Saudi workers monthly average wage in four sectors: 10.238 SAR. The general authority for statistics; 2020. Available from: https://www.stats.gov.sa/en/news/292\#: :text=The\%20General $\% 20$ Authority $\% 20$ for $\% 20$ Statistics,non $\% 2$ Dprofit $\% 20$ organizations $\% 2 \mathrm{C} \% 20$ international\%20and. Accessed July 17, 2020.

58. U.S. Bureau of Labor Statistics. Occupational employment and wages, may 2019; 2020. Available from: https://www.bls.gov/oes/ current/oes291051.htm. Accessed July 17, 2020.

59. U.S. Bureau of Labor Statistics. Economic news release usual weekly earnings summary; 2020. Available from: https://www.bls.gov/news. release/wkyeng.nr0.htm. Accessed July 17, 2020.

60. Development MoHRaS. Labor Law. Ministry of human resources and social development; 2016. Available from: https://hrsd.gov.sa/sites/ default/files/LABOR\%20LAW.pdf. Accessed July 17, 2020.

61. Baruch GK, Biener L, Barnett RC. Women and gender in research on work and family stress. Am Psychol. 1987;42(2):130-136. doi:10.1037/0003-066X.42.2.130

62. Afolabi OA, Dahunsi OB. Work stress adaptation: roles of gender, social support and personality. Afr J Psychol Stud Soc Issues. 2014;16 (2):166-177.

63. Kim JE, Song IH, Lee S-H. Gender differences of stressful life events, coping style, symptom severity, and health-related quality of life in patients with panic disorder. J Nerv Ment Dis. 2017;205 (9):714-719. doi:10.1097/NMD.0000000000000696

64. Andrisano-Ruggieri R, Capunzo M, Crescenzo P, et al. Inconsistency of sentinel events and no gender difference in the measurement of work-related stress. Sage Open. 2016;6(1):2158244016629527. doi:10.1177/2158244016629527

65. De Jonge J, Bosma H, Peter R, et al. Job strain, effort-reward imbalance and employee well-being: a large-scale cross-sectional study. Soc Sci Med. 2000;50(9):1317-1327. doi:10.1016/S02779536(99)00388-3

66. Greenhaus JH, Beutell NJ. Sources of conflict between work and family roles. Acad Manag Rev. 1985;10(1):76-88. doi:10.5465/ amr.1985.4277352

67. Stanescu S, Kirby SE, Thomas M, et al. A systematic review of psychological, physical health factors, and quality of life in adult asthma. NPJ Prim Care Respir Med. 2019;29(1):1-11. doi:10.1038/ s41533-019-0149-3

68. Pengpid S, Peltzer K. The impact of chronic diseases on the quality of life of primary care patients in Cambodia, Myanmar and Vietnam. Iran J Public Health. 2018;47(9):1308-1316.

69. Lam CL, Lauder IJ. The impact of chronic diseases on the health-related quality of life (HRQOL) of Chinese patients in primary care. Fam Pract. 2000;17(2):159-166. doi:10.1093/fampra/17.2.159

70. Tüzün H, Aycan S, İlhan MN. Impact of comorbidity and socioeconomic status on quality of life in patients with chronic diseases who attend primary health care centres. Cent Eur J Public Health. 2015;23(3):188-194.

71. Wrosch C, Scheier MF. Personality and quality of life: the importance of optimism and goal adjustment. Qual Life Res. 2003;12(1):59-72. doi:10.1023/A:1023529606137

72. Fang -Y-Y, Huang C-Y, Hsu M-C. Effectiveness of a physical activity program on weight, physical fitness, occupational stress, job satisfaction and quality of life of overweight employees in high-tech industries: a randomized controlled study. Int J Occup Saf Ergon. 2019;25 (4):621-629. doi:10.1080/10803548.2018.1438839 


\section{Publish your work in this journal}

Risk Management and Healthcare Policy is an international, peerreviewed, open access journal focusing on all aspects of public health, policy, and preventative measures to promote good health and improve morbidity and mortality in the population. The journal welcomes submitted papers covering original research, basic science, clinical \& epidemiological studies, reviews and evaluations, guidelines, expert opinion and commentary, case reports and extended reports. The manuscript management system is completely online and includes a very quick and fair peer-review system, which is all easy to use. Visit http://www.dovepress.com/testimonials.php to read real quotes from published authors. 